11. Kristie L Bell, Roslyn N Boyd, Sean M Tweedy, Kelly A Weir, Richard D Stevenson, Peter SW Davies A prospective, longitudinal study of growth, nutricion and sedentary behavior in young children with cerebral palsy // Public Health 2010, 10:179.

12. Peter L. Rosenbaum, Stephen D. Walter, Steven E. Hanna, Robert J. Palisano, Dianne J. Russell, Ellen Wood, Doreen J. Bartlett, Barbara E. Galuppi. Prognosis for Gross Motor Function in Cerebral Palsy Creation of Motor Development Curves // JAMA. 2002; 288(11): 1357-1363 (DOI: 10.1001/jama.288.11.1357).

13. Romano C., van Wynckel M., Hulst J., Broekaert I., Bronsky J., Dall'Oglio L. et al. European Society for Paediatric Gastroenterology, Hepatology and Nutrition Guidelines for the Evaluation and Treatment of Gastrointestinal and Nutritional Complications in Children With Neurological Impairment. J Pediatr Gastroenterol Nutr 2017; 65: 242-264. DOI: 10.1097/ MPG.0000000000001646.

14. Steven E Hanna, Doreen J Bartlett, Lisa M Rivard, Dianne J Russell. Reference urves for the Gross Motor Function Measure: Percentiles for Clinical Description and Tracking Over Time Among Children With Cerebral // Palsy Physical Therapy. Volume 88. Number 5. May 2008: 596-607.

15. Toivo Jürimäe, Jaak Jürimäe. Growth, physical activity, and motor development in prepubertal children. CRC Press. Boca Raton London New York Washington, D.C. 2000. P. 201.

16. Christine Imms, Iona Novak, Claire Kerr, Melinda Randall, Adrienne Harvey, H Kerr Graham, Dirah Reddihough. Improving allied health professionals' research implementation behaviours for children with cerebral palsy: protocol for a beforeafter study // Implementation Science, 2015, 10:16 DOI 10.1186/s13012-014-0202-0.

17. Morag J Andrew, Jeremy R Parr, Chris Montague-Johnson, Oliver Braddick, Karen Laler, Nicola Williams, Bonny Baker, Peter Sullivan Optimising nutrition to improve growth and reduce neurodisabilities in neonates at risk of neurological impairment, and children with suspected or confirmed cerebral palsy // BMC Pediatrics, 2015. 15:22.

18. Patrick G. McPhee, Joyce L Benner, Astrid C.J. Balemans, Olaf Verschuren, Rita J.G van den Berg-Emons, Edvard A. Hurvitz, Mark D. Peterson, Wilma M.A van der Slot, Marij E. Roebroeck, Jan Willem Gorter Multimorbidity risk assessment in adolescents and adults with cerebral palsy: a protocol for establishing a core outcome set for clinical research and practice // Trials (2019) 20:176 doi.org/10.1186/s13063-019-3265-z.

19. Rosalie Power, Rahena Akhter, Mohammad Muhit, Sabrina Wadud, Eamin Heanoy, Tasnnem Karim, Nadia Badaw, Gulam Khandaker A quality of life questionnaire for adolescents with cerebral palsy: psychometric properties of the Bengali CPQoL-teens // Health and Quality of Life Outcomes, 2019, 17:135 doi.org/10.1186/s12955-019-1206-X.

20. Eun-Young Park Relationship between activity limitation and health-related quality of life in school-aged children with cerebral palsy: a cross-sectional study // Health and Quality of Life Outcomes, 2017, 15:87 DOI 10.1186/s12955-017-0650-8.

Умирова С.М., Сабирова Ш.Б.

\title{
Применение нейропротекторов в восстановлении двигательных функций у больных после ишемического инсульта
}

\begin{abstract}
Самаркандский Государственный медицинский институт, кафедра медицинской реабилитации, спортивной медицины и народной медицины, г. Самарканд, Республика Узбекистан
\end{abstract}

Ишемический инсульт - это острая недостаточность мозгового кровообращения, влекущая за собой нарушения неврологических функций. Острый ишемический инсульт возникает из-за закупорки сосуда тромбом, или эмболом. Из-за нарушенного кровообращения участки головного мозга гибнут, а те функции, которые они контролировали, нарушаются. Более $50 \%$ больных, перенесших инсульт, имеют двигательные нарушения различной степени выраженности, 30\% становятся тяжелыми инвалидами и не могут передвигаться без посторонней помощи.

Цель - изучение эффективности применения Церабин-Ц в терапии двигательных нарушений после ИИ.
Материалы и методы. В исследование были включены 60 больных с ИИ, 35 мужчин и 25 женщина, в возрасте от 40 до 75 лет. Критериями включения больных в исследование были: инфаркт в левом полушарии большого мозга с развитием гемипареза разной степени выраженности и нарушений походки; острый (5-16-е) сутки и ранний восстановительный (1-2 мес.) периоды инсульта. Локализация и характер очаговых изменений мозга подтверждались данными рентгеновской компьютерной (КТ) или магнитно-резонансной (МРТ) томографии головного мозга. Инфаркты мозга локализовались в левом полушарии большого мозга в бассейне средней мозговой артерии. Выраженность неврологических нарушений оценивалась по шкале 
NIHSS. Степень двигательных нарушений в ноге и руке оценивалась раздельно по соответствующим субшкалам. Больным назначалась базисная медикаментозная терапия. Базисная терапия инсульта направлена, по сути, на поддержание основных жизненно-важных функций организма. Базисная медикаментозная терапия включает в себя обеспечение адекватного дыхания, коррекцию АД и нарушений сердечно-сосудистой деятельности, поддержание кровообращения, контроль и коррекцию водно-электролитных нарушений, уменьшение отека мозга, профилактику и лечение пневмонии. Всем пациентам проводился массаж паретичных конечностей. Основную (1-ю) группу составили 35 пациентов, которым Церабин-Ц назначался в остром периоде ИИ (5-16-е сутки); группу сравнения (2-ю) - 25 пациентов, которым Церабин-Ц назначался в раннем восстановительном периоде (1-2мес после перенесенного ИИ).

Результаты. Тяжесть неврологических нарушений соответствовала умеренной и тяжелой в обеих группах больных. В неврологическом статусе у всех больных определялись двигательные нарушения (спастический гемипарез) в сочетании с парезом мимической мускулатуры, чувствительными нарушениями. У больных 1-й группы при МРТ были выявлены инфаркты в бассейне левой средней мозговой артерии. Степень неврологических нарушений по шкале инсульта NIHSS составляла 12 баллов. Степень двигательных нарушений в руке была 8, а в ноге - 16 баллов. У 20 больных 2-й группы были выявлены инфаркты в бассейне левой средней мозговой артерии корково - подкорковой локализации, а у 10 - глубинной локализации. Выраженность неврологических нарушений по NIHSS составляла 11 баллов. Степень двигательных нарушений в руке была - 9, в ноге - 18 баллов. В обеих группах после курса лечения Церабин-Ц наблюдалось уменьшение двигательных нарушений в руке и ноге. Умеренное восстановление двигательных функций отмечалось в 78\% случаев при начале лечения Церабин-Ц в остром периоде и в 50\% - при начале лечения в раннем восстановительном периоде. Минимальное восстановлении двигательных функций наблюдалось в 22\% случаев при начале лечения Церабин-Ц в остром периоде и в 50\% - при начале лечения в раннем восстановительном периоде. Восстановление двигательных функций паретичных конечностей было значительно лучше при начале лечения Церабин-Ц в остром периоде ИИ.

Выводы. Проведенное исследование показало, что в остром периоде ИИ после курса лечения Церабин-Ц наблюдаются уменьшение степени неврологических нарушение по шкале NIHSS, уменьшение двигательных нарушение так в руке, так и ноге. В остром периоде ИИ после курса лечения Церабин-Ц отмечается уменьшение двигательных нарушений при значительно выраженном и умеренном парезе в ноге. В острым и раннем восстановительном периодах ИИ после курса лечения Церабин-Ц выявлено уменьшение степени двигательных нарушений в руке.

Ключевые слова: инсульт, мозгового кровообращения, тромб, эмбол, сосуд.

\section{Литература}

1. Анализ эффективности применения актовегина, церебролизина, гепарина и мексидола при лечении ишемического инсульта // Актуальные вопросы сосудистых заболеваний головного мозга сборник тезисов, докладов I I межобластной научно- практической конференции неврологов. Самарской и Оренбургской областей - Похвистнево, 2001. - С. 20-21. В соавт.с С.А.Уткиным.

2. Ашман, А.А. Принципы патогенетической терапии инфаркта мозга / А.А.Ашман, В.С.Суханин // Сборник статей 6 межобластной конференции неврологов Самарской и Оренбургской областей. Серноводск, 2003. C. 1621.

3. Валунов, О.А. Динамика очаговых неврологических нарушений у больных, перенесших ишемический инсульт / О.А.Валунов, Я.Н.Кушнеренко // Инсульт. Приложение к журналу неврологии и психиатрии имени С.С.Корсакова. - 2001. - Выпуск 5. - С. 17-21.

4. Банк данных по ишемическому инсульту основные результаты Текст. / Е.И.Гусев [и др.] // Неврологический журнал. - 2002. - №4. - С. 8-14.

5. Бархатова, В.П. Основные направления нейропротекции при ишемии мозга / В.П.Бархатова, 3.А.Суслина // Неврологический журнал. - 2002. - № 4. - С. 42-50.

6. Бегидова, Н.М. Течение и исходы ишемического инсульта у лиц молодого возраста / Н.М.Бегидова, С.М.Чудопал, М.Х.Тлапшоков // 9-й Всероссийский съезд неврологов: тезисы докладов. Ярославль, 2006. - С. 371.

7. Беймуханов Р.М., Сегизбаева Б.Т. Опыт применения больших доз церебролизина в лечении острой стадии инфаркта мозга.

8. Инсульт. Приложение к журналу неврологии и психиатрии имени С.С.Корсакова. - 2003. - Выпуск 9. C. 41-174.

9. Белкин, А.А. Современные аспекты эпидемиологии, патофизиологии, этиологии и классификации инсульта / А.А.Белкин, Л.И.Волкова // Уральский медицинский журнал. - 2005. - № 1. - С. 2-10.

10. Бодыхов, М.К. Свободные радикалы при ишемии головного мозга / М.К.Бодыхов, В.Н.Федоров, В.И.Скворцова // Инсульт. Приложение к журналу неврологии и психиатрии имени С.С.Корсакова. - 2004. Выпуск 10.- С. 3338. 
11. Бурдаков, В.В. Сравнительное моделирование ишемического инсульта как способ оптимизации антигипертензивной терапии / В.В. Бурдаков, И.И. Дегтярь // 9-й Всероссийский съезд неврологов: тезисы докладов. Ярославль, 2006. - С. 376.

12. Василенко, Ф.И. Осложненный инсульт концептуальная проблема современной ангионеврологии / Ф.И.Василенко // 8-й Всероссийский съезд неврологов: тезисы докладов. - Казань, 2001. - С. 209.

13. Верещагин, Н.В. Гетерогенность инсульта в клинической практике / Н.В. Верещагин // Журнал Атмосфера. Нервные болезни. - 2004. - №1. - С. 1920.

14. Герасимова М.М. Влияние кортексина на терапию острого периода ишемического инсульта / М.М.Герасимова // Кортексин пятилетний опыт отечественной неврологии / под ред. А.А.Скоромца, М.М.Дьяконовой. - СПб.: Наука, 2005. - С.59-63.

15. Виленский, Б.С. Неотложные состояния в неврологии: Руководство для врачей / Б.С.Виленский. СПб.: Фолиант, 2004. - 512 с.

Шарафова И.А.

\section{Нейровизуализация как современный метод диагностик и и прогноза реабилитации при поражении лицевого нерва у детей}

Самаркандский Государственный медицинский институт, кафедра медицинской реабилитации, спортивной медицины и народной медицины, г. Самарканд, Республика Узбекистан

Актуальность. По данным разных авторов, нейропатия лицевого нерва (НЛН) составляет около $3 \%$ заболеваний периферической нервной системы (1425 случаев на 100 тыс. населения), и не имеет гендерных различий, при этом заболеваемость в течении жизни варьирует. Идиопатические невропатии наблюдаются у $75 \%$ больных, отогенные - у 15\%, другой этиологии - у $10 \%$ больных. Но достоверных источников частоты возникновения, течения и прогноза НЛН у детей, ее распространения в весьма малом количестве $[3,5]$.

Основным симптомом заболевания, вне зависмости от топографии пораженного участка, является дефицит движения в мимических мышцах половины лица (прозопарез, прозоплегия). Объективно: лицо асимметрично, глазная щель шире и кожные складки сглажены на пораженной стороне, угол рта опущен, наблюдается лагофтальм, симптом Белла, надбровный и роговичные рефлексы снижены. Тяжесть поражения оценивается по степеням 6-балльной шкалой House Brackmann [2,3]. Клиническая симптоматика определяет диагноз и прогноз восстановления функции мимических мышц у пациентов с НЛН.

Электронейромиография (ЭНМГ), конечно же, является стандартом определения функционального состояния периферической нервной системы и широко используется как для подтверждения клинического диагноза и установления уровня поражения, так и прогноза течения и исхода заболевания. Нейровизуализация лицевого нерва в клинической практике используется редко, а использование ее методов с целью прогноза восстановления функции лицевого нерва при НЛН не изучено. Интракраниальную часть лицевого нерва визуализируют с помощью компьютерной томографии, экстракраниальную часть можно хорошо визуализировать с помощью ультразвукового исследования нейросонографии (НСГ). НСГ экстракраниальной части черепных нервов - новый, развивающийся метод диагностики в режиме реального времени с использованием датчиков высокого разрешения.

Отсутствие в профессиональной литературе систематизированных сведений о применении НСГ в сочетании с ЭНМГ и лечебной гимнастикой, моделированием мышечно-фасциального сегмента у детей, которые составляют основу реабилитационных комплексов при НЛН, серьезно ограничивает возможности оценки их эффективности $[4,5]$.

Цель - изучить корреляцию между параметрами ЭНМГ и НСГ лицевого нерва у детей с идиопатической НЛН с благоприятным и неблагоприятным течением процесса реабилитации.

Исследования и клинические наблюдения больных проводились в отделении физиотерапии Клиники Самаркандского государственного медицинского института №1 (г. Самарканд). Для решения поставленных задач было обследовано 52 больных детей в остром периоде заболевания (основная группа) и 36 детей из контрольной группы сравнения. В основной группе: мальчиков - 19 (37\%), девочек - 33 (63\%). Возраст составил от 5 до 15 лет (средний возраст $11,7 \pm 4,3$ года). В контрольной группе сравнения у детей в анамнезе не наблюдалось признаков НЛН и при клиническом обследовании не обнаружено очаговой неврологической симптоматики. При осмотре отмечались степень пареза, нарушение чувствительности, 